\title{
Irradiation-induced Effects of proton irradiation on zirconium carbides with different stoichiometry
}

Y. Huang ${ }^{1,2 *}$, B.R. Maier ${ }^{2}$ and T.R. Allen 2,3

\begin{abstract}
Zirconium carbide $(\mathrm{ZrC})$ is being considered for utilization in deep burn TRISO fuel particles for high-temperature, gas-cooled reactors. Zirconium carbide has a cubic B1 type crystal structure along with a very high melting point $\left(3420^{\circ} \mathrm{C}\right)$, exceptional hardness and good thermal and electrical conductivities. Understanding the $\mathrm{ZrC}$ irradiation response is crucial for establishing $\mathrm{ZrC}$ as an alternative component in TRISO fuel. Until now, very few studies on irradiation effects on $\mathrm{ZrC}$ have been released and fundamental aspects of defect evolution and kinetics are not well understood although some atomistic simulations and phenomenological studies have been performed. This work was carried out to understand the damage evolution in floatzone refined $\mathrm{ZrC}$ with different stoichiometries. Proton irradiations at $800^{\circ} \mathrm{C}$ up to doses of $3 \mathrm{dpa}$ were performed on $\mathrm{ZrC}_{\mathrm{x}}$ (where $\mathrm{x}$ ranges from 0.9 to 1.2) to investigate the damage evolution. The irradiation-induced defects, such as density of dislocation loops, at different stoichiometries and doses which were characterized by transmission electron microscopy (TEM) is presented and discussed.
\end{abstract}




\section{Introduction}

Zirconium carbide $(\mathrm{ZrC})$ is being considered for utilization in deep burn Tristructuralisotropic (TRISO) fuel particles in high temperature gas cooled reactors. Zirconium carbide has a cubic B1 type crystal structure along with a very high melting point $\left(3420^{\circ} \mathrm{C}\right)$, exceptional hardness and good thermal and electrical conductivities [1-4]. Evaluating and understanding the irradiation response of $\mathrm{ZrC}$ is essential for establishing it as a TRISO fuel component. Until now, very few studies on irradiation effects on $\mathrm{ZrC}$ [11] have been published and the fundamental aspects of defect evolution and kinetics are not well understood although some atomistic simulation and phenomenological studies have been performed [5-10].

Previous phase-stability work shows that when the ratio between $C$ and $Z r$ exceeds 1 (as in Figure 1) the microstructure should be crystalline gamma phase $\mathrm{ZrC}$ combined with pockets of free carbon or graphite. Stoichiometry is therefore a critical factor for determination of $\mathrm{ZrC}_{\mathrm{x}}$ properties for both un-irradiated and irradiated materials [11-15]. Thus, the stoichiometric change will likely be an important factor when studying the irradiation behavior of ZrC. However, until now, little work has been done on the stoichiometric effect on the irradiation behavior of $\mathrm{ZrC}$. This work was carried out to understand the damage evolution in $\mathrm{ZrC}$ with different stoichiometries at $800^{\circ} \mathrm{C}$ using proton irradiation. Float-zone refined $\mathrm{ZrC}_{\mathrm{x}}$ (where $\mathrm{x}$ ranges from 0.9 to 1.2 in 0.1 increments) was selected for this investigation because of its high purity. The irradiation-induced defects, such as density of dislocation loops and voids at various stoichiometries and doses were examined.

\section{Experiments}

Commercial grade zone refined $\mathrm{ZrC}_{\mathrm{x}}$ rods were obtained from APTech Inc. The initial stock is either hot-pressed or sintered material and fabricated from $>99.5 \%$ pure powder. The stoichiometry of the final refined material can be modified by adjusting this initial stock. This material is then cut into appropriately sized strips with an abrasive diamond cutter. These strips are then placed into a refining chamber evacuated to $<5 \mathrm{x}$ 
$10^{-6}$ torr and then back-filled to a pressure of 1 atm with argon gas. A heater is used to locally melt the strip while moving back and forth over the sample.

The as-received zone refined $\mathrm{ZrC}_{\mathrm{x}}$ ceramic rods with $3 \mathrm{~mm}$ diameter were sectioned using a low speed diamond saw into disks with an initial thickness of around $450 \mu \mathrm{m}$. These disks were then mechanically ground down to a thickness of about $300 \mu \mathrm{m}$ using successively finer polishing steps of $15 \mu \mathrm{m}, 9 \mu \mathrm{m}, 6 \mu \mathrm{m}, 3 \mu \mathrm{m}, 1 \mu \mathrm{m}, 0.5 \mu \mathrm{m}$, and 0.25 $\mu \mathrm{m}$. Finally the samples were polished with $0.05 \mathrm{um}$ colloidal silica, which yielded a smooth, reflective surface.

Prior to irradiating the samples, an ion damage simulation was performed using the widely available Stopping Ranges of lons in Matter (SRIM) 2011 software with the threshold displacement energies of $25 \mathrm{eV}$ for carbon and $35 \mathrm{eV}$ for zirconium [1] and the density is $6.73 \mathrm{~g} / \mathrm{cm}^{3}$. Figure 2 is a graph containing the vacancy production rates, for all the stoichiometries investigated, as a function of depth into the sample from where the ions first impinge upon the surface. This figure shows that the vacancy production rate for $2.0 \mathrm{MeV}$ protons, which is the same irradiation energy in later experiment, in each of the $\mathrm{ZrC}$ stoichiometries being investigated was very similar up to a depth of around 20um. This consistency allowed the researchers to define a single desired fluence while knowing that the dose for each stoichiometry would be similar. The region of interest in the samples for the irradiation behavior study is at the depth around $15 \mu \mathrm{m}$ below the surface of the sample in the region with the relatively constant vacancy production rate. The dose rate from 5 to 20 um was calculated to be approximately $4.7 \times 10^{-5} \mathrm{dpa} / \mathrm{s}$.

Figure 3 is the as-polished samples loaded onto the stage and clamped done with the face-plate. Three thermocouples recorded the temperature of that stage during the irradiation as indicated.

The irradiation was performed at University of Wisconsin Ion Beam Lab. The National Electrostatics Corp. Pelletron Accelerator (Model 5SDH4) Accelerator was used with Torodial Volume lon Source (TORVIS). 
The samples were irradiated at an average temperature of $800^{\circ} \mathrm{C}$ and the temperature deviated about $10^{\circ} \mathrm{C}$ during the run and ion beam flux is about $1 \times 10^{18} \mathrm{ion} / \mathrm{cm}^{2} \cdot \mathrm{s}$. The temperature of the stage was monitored constantly during the experiment with three thermocouples secured to the faceplate of the irradiation stage, shown in Figure 3.

Infrared camera is used to monitor temperature change and specimen's status. Figure 4 is an example of infrared image of the samples under irradiation. The example shows that the samples were heated quite uniformly since most of the samples are the same color and two samples in the upper left and one in the right middle appear to have disappeared. It is interesting to note that two samples in the upper left hand corner of the image appear to missing. However, when the stage was opened after $1 \mathrm{dpa}$, the samples remained intact. While the infrared (IR) camera may have given a general idea of where the beam was heating, it was not reliable to determine if the samples were still intact. The parameters of the beam and general operational notes were recorded during the experiment to help maintain the same conditions between runs. All of the samples were irradiated to $1 \mathrm{dpa}$. Once finished with $1 \mathrm{dpa}$, a sample for each stoichiometry was removed and the stage replaced back on the beamline to irradiate to the next dose.

Two or three different dose irradiations were performed on $\mathrm{ZrC}_{\mathrm{x}}$ at $800^{\circ} \mathrm{C}$ and after irradiation, the specimens were dimpled, starting from the un-irradiated face, until the center thickness was 25-30 $\mu \mathrm{m}$ as indicated by the dimpling machine which was confirmed with the Zygo New View White Light Interferometer. A resultant Zygo measurement is displayed in Figure 4 below. Finally, ion milling by Fischion 1010 with energies ranging from $5 \mathrm{kV}$ to $3 \mathrm{kV}$ and angles ranging from $15^{\circ}$ to $6^{\circ}$ were carried out to ensure the specimen was thin enough for transmission electron microscopy (TEM) observation. The TEM characterization was performed using a Philips CM200UT TEM. The SEM microstructure of the irradiated and un-irradiated specimens was characterized with a Zeiss 1540XB Cross Beam Focused Ion Beam.

3. Results

3.1 SEM 
Before irradiation, the porosity and the grain size distribution were examined using scanning electron microscopy (SEM) and energy-dispersive spectroscopy (EDS). $\mathrm{ZrC}_{0.9}$ shows large grains after zone refinement and quite a few defects inside the grains and along grain boundaries (Images $\mathrm{A}$ and $\mathrm{B}$ in Figure 5). However, $\mathrm{ZrC}_{1.0}$ images (Images $C$ and $D$ in Figure 5) show an increase in impurities inside of the grains. After studied by EDS, these impurities are found to be carbon particles which are suspected from manufacture process. Comparing the lower $\mathrm{C}$ containing sample images with the $\mathrm{ZrC}_{1.1}$ and $\mathrm{ZrC}_{1.2}$ images (Images $\mathrm{E}, \mathrm{F}, \mathrm{G}$ and $\mathrm{H}$ in Figure 5), it is shown that more "crack-like" second phases are present along the grain boundaries and inside of individual grains than the $\mathrm{ZrC}_{0.9}$ and $\mathrm{ZrC}_{1.0}$. This phenomenon is likely attributed to the increase in the $\mathrm{C}$ content for these samples [22] [23]. Figure 6 shows EDS elemental maps from $\mathrm{ZrC}_{1.2}$ which illustrates that grain boundaries are enriched with carbides (graphite). In addition, the inside of the gamma phase in $\mathrm{ZrC}_{1.2}$ also contains areas of graphite as expected.

After the irradiation, cross-sections of the irradiated surface were examined by forming trenches into the exposed face of the sample using ion milling with a focused ion beam. Upon inspection of the cross-section, a thin oxidation layer was found, an example of which is shown in Figure 7. Meanwhile, no significant changes were observed on grain boundaries after proton irradiation as shown in Figure 7.

\subsection{TEM}

All the irradiated specimens were examined at different magnifications with TEM to investigate the existence of dislocation loops, precipitates and voids. Only some ion milling damage on the surface was observed in the un-irradiated specimens as presented in Figure 8.

Figure 9 displays images of the dislocation loops of irradiated $\mathrm{ZrC}_{\mathrm{x}}$ with varying stoichiometries and doses after the $800^{\circ} \mathrm{C}$ irradiation (NA means the sample is broken or lost during the experiment). The images were taken close to the [011] zone axis under a $\mathrm{g}=200$, 2-beam bright field condition and loop size were measured by diameter.. Table 1 presents the numerical analysis of the dislocation loop densities from the TEM data. $\mathrm{ZrC}_{1.0}$ at $1 \mathrm{dpa}$ exhibits the highest density, $9.7 \times 10^{21} / \mathrm{m}^{3}$ while $\mathrm{ZrC}_{0.9}$ at $3 \mathrm{dpa}$ 
shows the lowest density, $3.2 \times 10^{21} / \mathrm{m}^{3}$. For the average loop size, $\mathrm{ZrC}_{1.1}$ at $2 \mathrm{dpa}$ exhibits the largest loop size which is $28.3 \mathrm{~nm}$ and $\mathrm{ZrC}_{1.1}$ at $1 \mathrm{dpa}$ shows the smallest loop size, $6.9 \mathrm{~nm}$. The size distributions of dislocation loops in the irradiated $\mathrm{ZrC}_{\mathrm{x}}$ samples are displayed in Figure 10. It appears that higher doses tend to exhibit a larger width of the loop size distribution for $\mathrm{ZrC}_{0.9}, \mathrm{ZrC}_{1.0}$ and $\mathrm{ZrC}_{1.1}$, a similar trend as published in Yang et. al.[1]. However, $\mathrm{ZrC}_{1.2}$ at $1 \mathrm{dpa}$ behaves differently compared to the other stoichiometries, the 1dpa sample has a loop size distribution which is wider than the 2dpa and 3dpa samples. Figure 11 shows the average size and density of dislocation loops in irradiated $\mathrm{ZrC}_{0.9}, \mathrm{ZrC}_{1.0}, \mathrm{ZrC}_{1.1}$ and $\mathrm{ZrC}_{1.2}$. This figure displays that for the sample with stoichiometries of $\mathrm{ZrC}_{0.9}, \mathrm{ZrC}_{1.0}$, and $\mathrm{ZrC}_{1.1}$, the average loop size increases and the loop density decreases with an increase in the dose. However $\mathrm{ZrC}_{1.2}$ exhibits the opposite trend in which the average size decreases and density increases as the dose increases. At $1 \mathrm{dpa}, \mathrm{ZrC}_{1.0}$ contains the highest density of loops, $9.7 \times 10^{21} /$ $\mathrm{m}^{3}$ and $\mathrm{ZrC}_{1.2}$ exhibits the largest average loop size, $15.1 \mathrm{~nm}$; at $2 \mathrm{dpa}, \mathrm{ZrC}_{1.2}$ shows the highest density while $\mathrm{ZrC}_{1.1}$ contains largest average loops size, $28.3 \mathrm{~nm}$; at $3 \mathrm{dpa}$, comparing $\mathrm{ZrC}_{1.2}$ to $\mathrm{ZrC}_{0.9}$, the loop density increases as the stoichiometry increases while the average loop size decreases.

\section{Discussion}

TEM results of the un-irradiated $\mathrm{ZrC}_{\mathrm{x}}$ used in this study reveal a material essentially free of defects and voids. After proton irradiation at $800^{\circ} \mathrm{C}$, a significant amount of dislocation loops were introduced in $\mathrm{ZrC}_{\mathrm{x}}$ and no obvious voids were observed.

A number of references published have reported the effects of ion irradiation on microstructure evolution in ZrC [1], [12]-[14], [16]-[21]. The most typical irradiationdefect microstructures contain black dots or dislocation networks at room temperature implantations. Also for proton or $\mathrm{Kr}$ irradiation at higher temperature $\left(>800{ }^{\circ} \mathrm{C}\right)$, larger dislocation loops are identified.

In this study, it is shown that if the atomic ratio of $\mathrm{Zr}$ to $\mathrm{C}$ in $\mathrm{ZrC}_{\mathrm{x}}$ is smaller than 1.2, such as $0.9,1.0$ or 1.1 , dislocation loops grow bigger i.e. the average loop size increases and there density is reduced as the dose is increased. As the stoichiometry 
reaches 1.2, more loops form meaning the density of these loops increases while the average loop size decreases with an increase in dose. There is an abnormal observation for the $\mathrm{ZrC}_{1.1}$ sample at 2 dpa where the average loop size dramatically increases to $28.3 \mathrm{~nm}$, much larger than any other condition presented. However, the reason for this abrupt change is unclear, it could possibly be associated with a dramatic localized temperature change during the irradiation or perhaps the local stoichiometry is not consistent. From the loop size distribution results, it is demonstrated that a higher dose broadens the size distribution, which shifts the average loop size upward until the stoichiometry reaches 1.2. The $\mathrm{ZrC}_{1.2}, 1 \mathrm{dpa}$ owns the broadest size distribution and results in the largest average loop size.

The results indicate stoichiometry's effect on the microstructure of $\mathrm{ZrC}_{\mathrm{x}}$ is obvious either before or after irradiation. The carbon incorporation due to $\mathrm{Zr} / \mathrm{C}$ ratio resulting into different lattice parameter and graphitic carbon phase before irradiation is studied by Chinhaka Silva, et al [24] and from our study, $\mathrm{Zr} / \mathrm{C}$ ratio also has a strong effect on microstructure evolution after irradiation. The reverse trend of loop density and size at ratio equals to 1.2 is suspected to be like this: When ratio is below and equal to 1.1 , less carbon interstitial atoms are introduced after irradiation to help form and grow dislocation loop. So the small loops merged into each other as dose increasing which results into size increasing and density decreasing. When ratio equals to 1.2 , the graphitic carbon phase shows highest amount which does not bonded to the $\mathrm{Zr}$ atoms. More carbon interstitial atoms at this ratio can help to form and grow the dislocation loop that makes the loop density and size both increase as a function of dose.

According to literature [11], there is a critical temperature in which loop formation transitions from frank loops to prismatic loops. In this work, the researchers haven't confirmed which type of dislocation loops are dominant in the different $\mathrm{ZrC}_{\mathrm{x}}$ stoichiometries but will be investigated in future work. High-resolution transmission electron microscopy (HRTEM) work will be conducted to identify the dislocation loop types. It is also possible that in the early stages of the irradiation, stacking fault tetrahedron (SFT) could be produced since ZrC has an FCC-structure, phenomenon which may be examined in future work. 


\section{Conclusion}

Microscopy results illustrate that refined $\mathrm{ZrC}_{\mathrm{x}}$ material after a proton irradiation at $800{ }^{\circ} \mathrm{C}$ is highly decorated with dislocation loops. The loop size and density is dependent both on dose and stoichiometry. $\mathrm{ZrC}_{1.2}$ shows quite different behavior compared to the lower C-ratio stoichiometries. However, no irradiation-induced voids were observed in any of the samples.

Further investigation is required to determine the nature of the dislocation loops. Precipitates and SFT are other possible irradiation-induced defects and should be studied. Mechanism simulation is expected to be carried out which will be related to different stoichiometry effects.

\section{Acknowledgement}

The authors would like to express their gratitude to Arthur Motta at Penn State University, Dane Morgan and Izabela Szlufarska at University of Wisconsin for their assistant on this research. This work is funded by Department of Energy through Nuclear Energy Research Intiative program (Project 10-679)

\section{References}

[1] Y. Yang, C. A. Dickerson, H. Swoboda, B. Miller, T. R. Allen, Journal of Nuclear Materials 378 (2008) 341

[2] C. Kral, W. Lengauer, D. Rafaja, P. Ettmayer, J. Alloy Compd. 265 (1998) 215.

[3] Y. Ozaki, R.H. Zee, Mater. Sci. Eng. A 202 (1995) 134.

[4] R. Evans, R. Jensen, M. Tishchenko, V. Daragan, AIP Conf. Proc. 301 (1994) 75.

[5] K. Minato, T. Ogawa, K. Fukuda, H. Sekino, I. Kitagawa, N. Mita, J. Nucl. Mater. 249 (1997) 142. 
[6] K. Sawa, S. Ueta, Nucl. Eng. Des. 233 (2004) 163.

[7] L.W. Hobbs, F.W. Clinard Jr., S.J. Zinkle, R.C. Ewing, J. Nucl. Mater. 216 (1994) 291.

[8] T. Ogawa, K. Fukuda, S. Kashimura, T. Tobita, F. Kobayashi, S. Kaod, H. Miyanishi,

I. Takahashi, T. Kikuchi, J. Am. Ceram. Soc. 75 (1992) 2985.

[9] K. Minato, T. Ogawa, Global (2003) 1068.

[10] K. Minato, T. Ogawa, Kazuhiro Sawa, Nucl. Technol. 130 (2000) 272.

[11] L. Snead, Y. Katoh, S. Kondo. Effects of fast neutron irradiation on zirconium carbide. v399, I2-3 (2010) 201

[12] G.W. Keilholtz, R.E. Moore and D.A. Dyslin, Fuels Mater. Develop. Quart. Prog. Rept., ORNL-4390 (1968) 113.

[13] D.A. Dyslin, R.E. Moore and H.E. Robertson, ORNL-4480 (1969) 245.

[14] G.W. Keilholtz, R.E. Moore and M.F. Osborne, Nucl. Appl. 4 (1968) 330.

[15] E.K. Storms and P. Wagner, High Temp. Sci. 5 (1973) 454.

[16] J. Gan, M.K. Meyer, R.C. Birtcher, T.R. Allen, J. ASTM Int. 3 (2006) 1.

[17] J. Gan, Y, Yang, C. Dicson, T. Allen, J. Nucl. Mater. 389 (2009) 317.

[18] R.A. Andrievskii, V.I. Savin, V.V. Ya Markin, V.T. Spravtsev, A.S. Shevcenko, Neorg. Mater. 14 (1978) 526.

[19] D. Gosset, M. Dolle, D. Simeone, G. Baldinozzi, I. Thorne, J. nucl. Mater. 373 (2008) 123.

[20] M.S. Kovalcheko, Y.I. Rogavoi, Neorganicheskie Materlaly 9 (1973) 321.

[21] M.L. Taubin, S.V. Fateev, M.V. Ivanov, P.V. Shutov, At. Energy. 70 (1991) 55.

[22] L.I. Gomozov, I. Sh. Akhmedzyanov, Soviet Atom. Energy 48 (1980) 413. 
[23] Loo.F.J.J. Van, W. Wakelkamp, G.F. Bastin, R. Metselaar, Solid State lonics, Diffusion \& Reactions. $32 \& 33$ (1989) 824. (pt. 2).

[24] Chinthaka Silva G.W., Kerche A.A, Hunn J.D., Martin R.C., Jellison G.E., Meyer H.M. J. of Solid State Chemistry, 194(2012)91-99

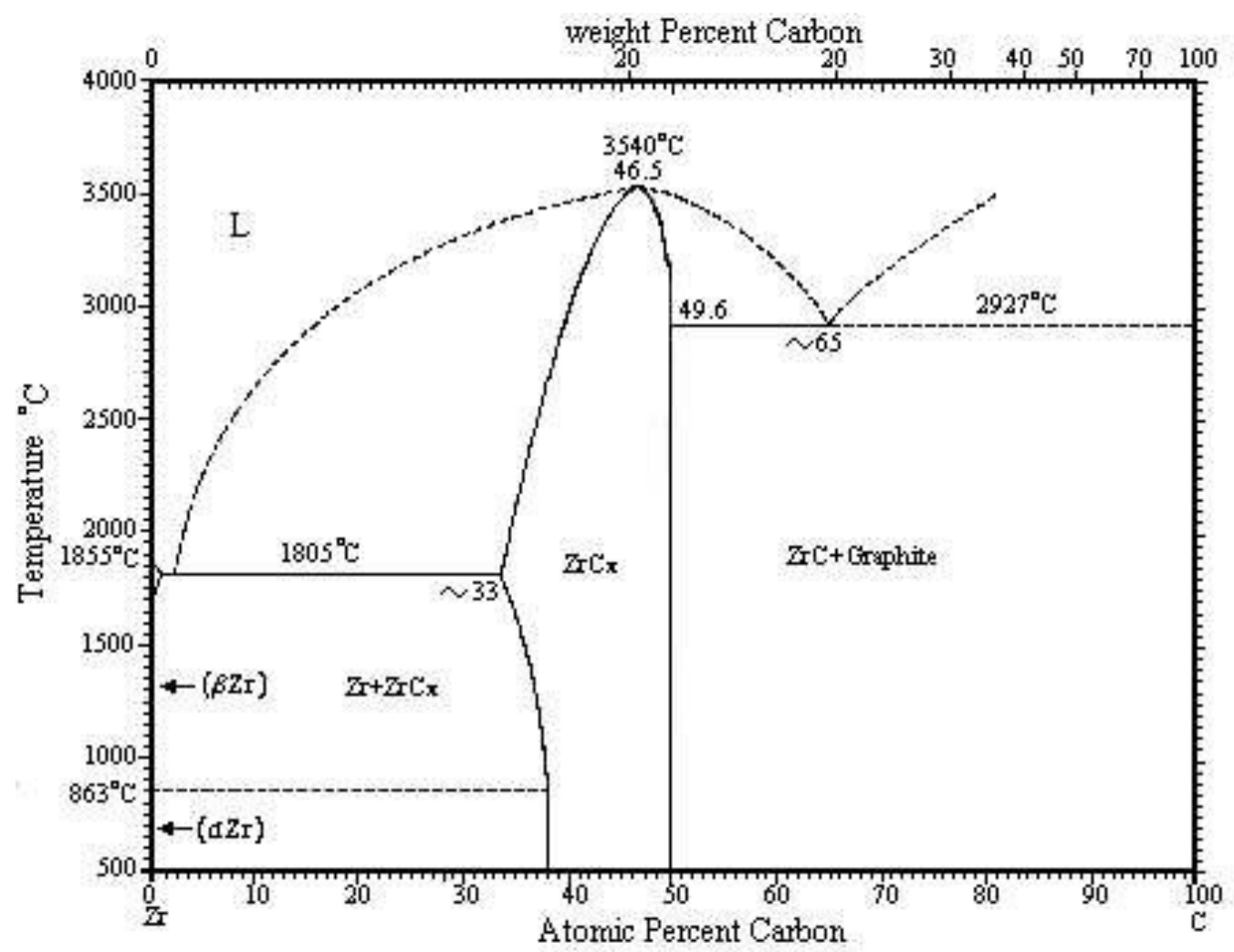

Figure 1. Phase Diagram of $\mathrm{Zr}-\mathrm{C}$ system which shows that above 50 at. $\% \mathrm{C}$, pockets of excess $C$ should be present [11]. 


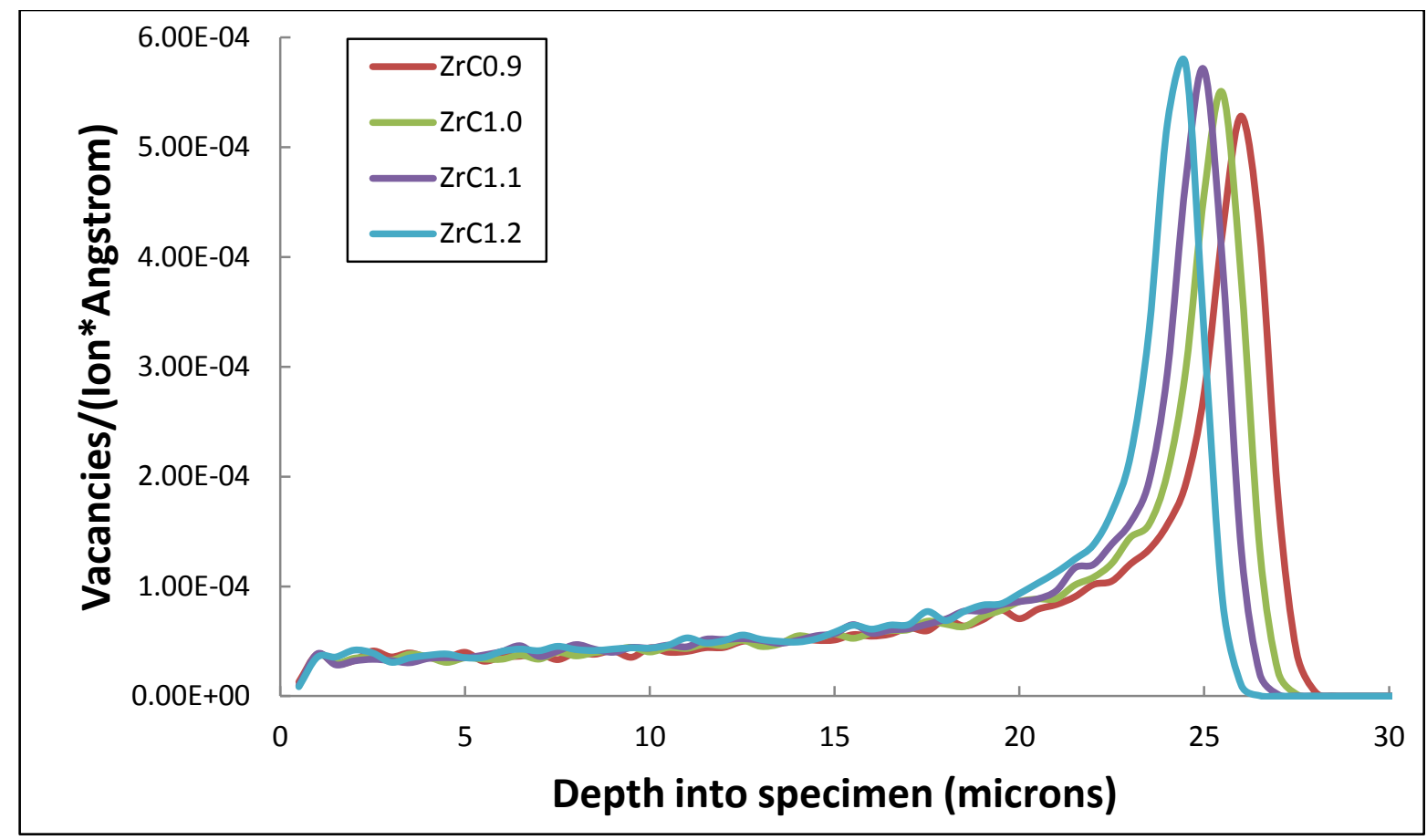

Figure 2. SRIM estimation of vacancy production rates in $\mathrm{ZrC}_{\mathrm{x}}$ irradiated by $2.0 \mathrm{MeV}$ protons.

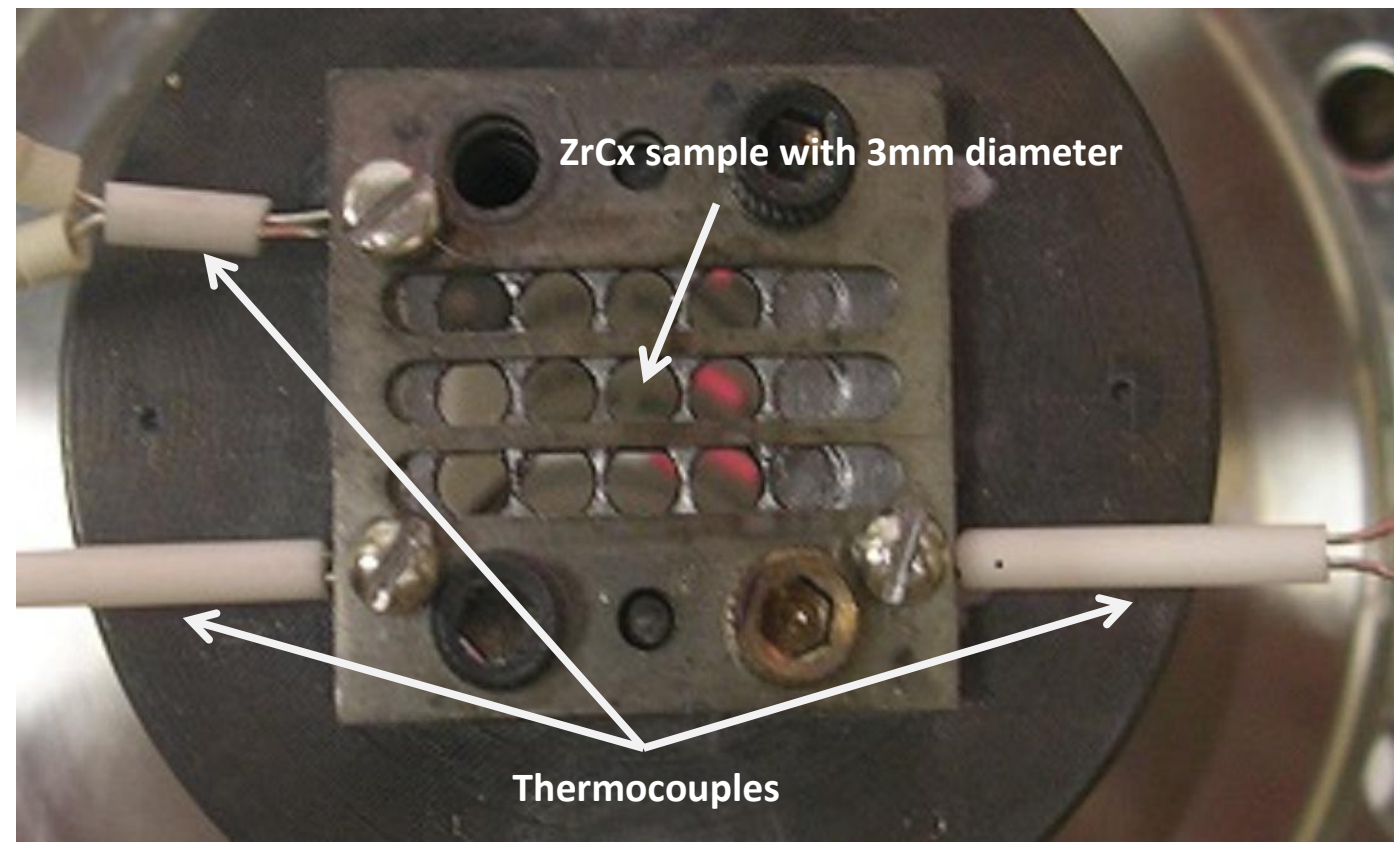

Figure 3. Sample stage with samples loaded and three thermocouples underneath recorded the temperature of that stage during the irradiation. 

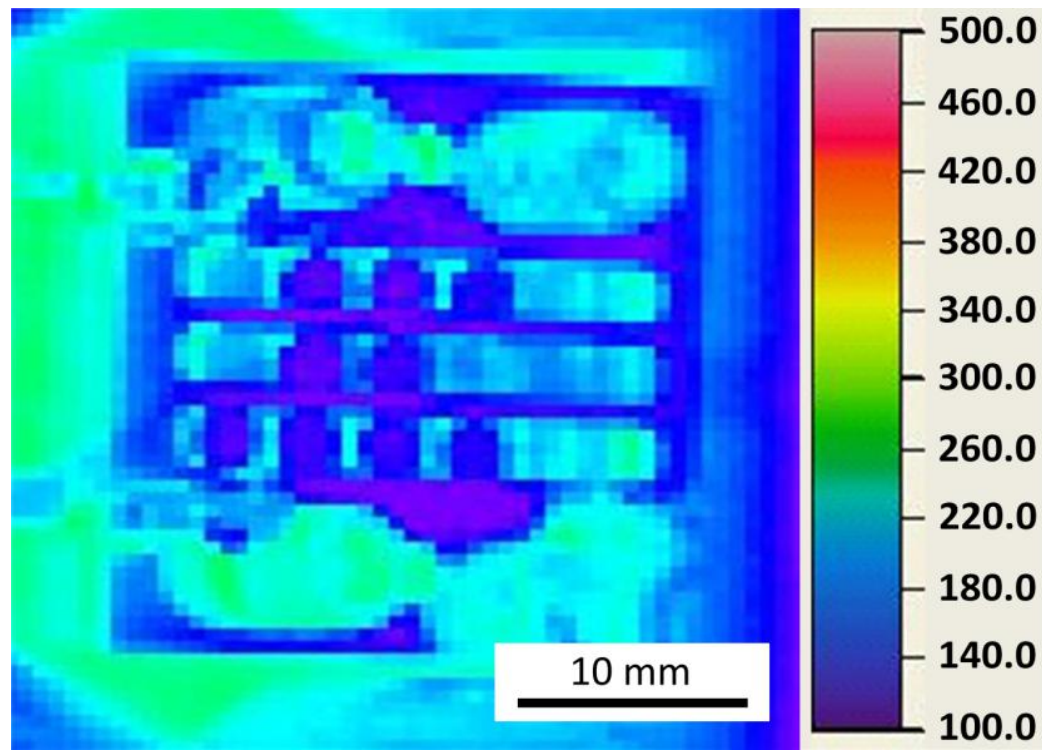

Figure 4. Example of an infrared image of the samples.

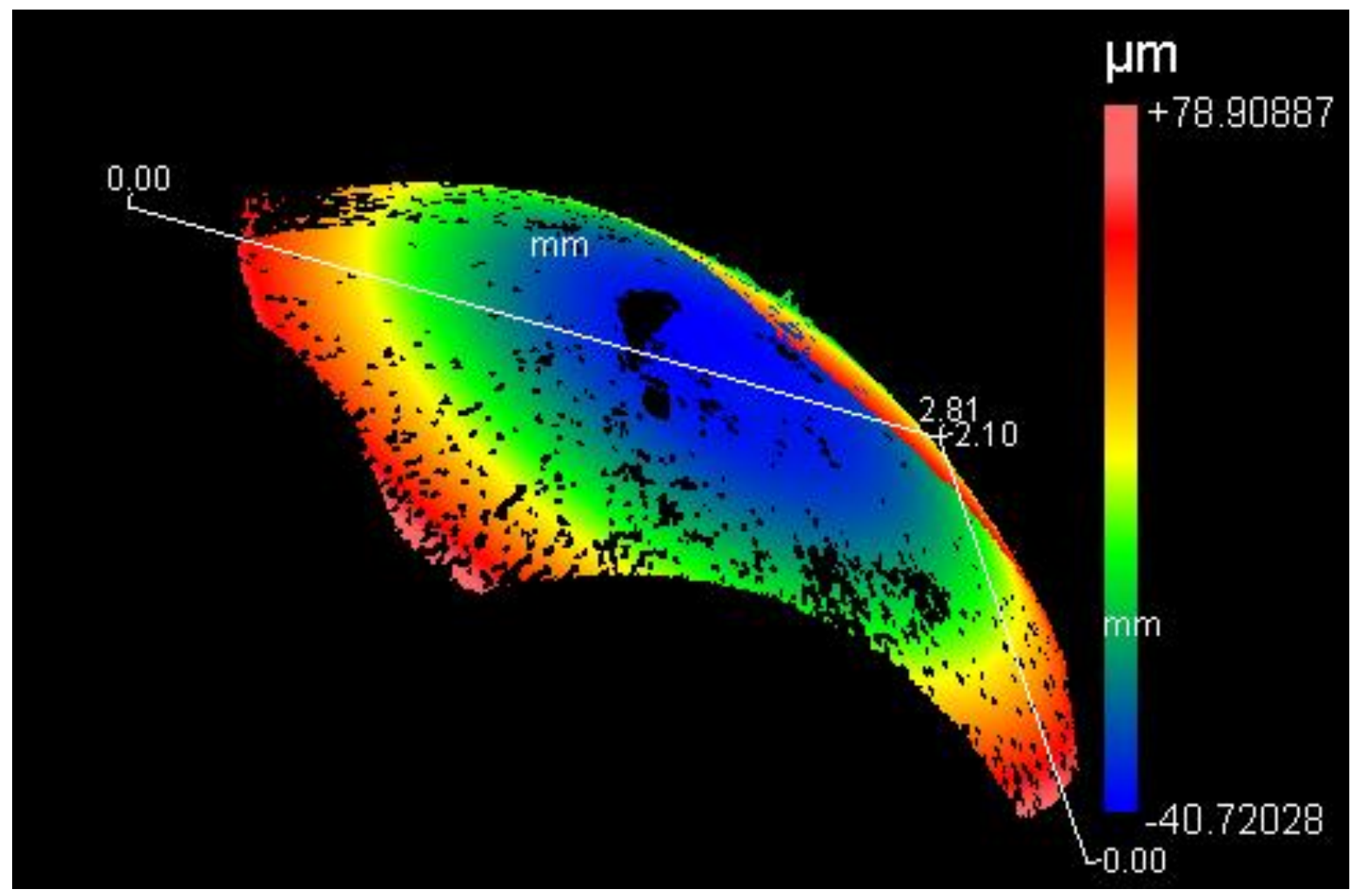

Figure 4. Example of depth measurement after dimpling by Zygo New View white light Interferometer. 

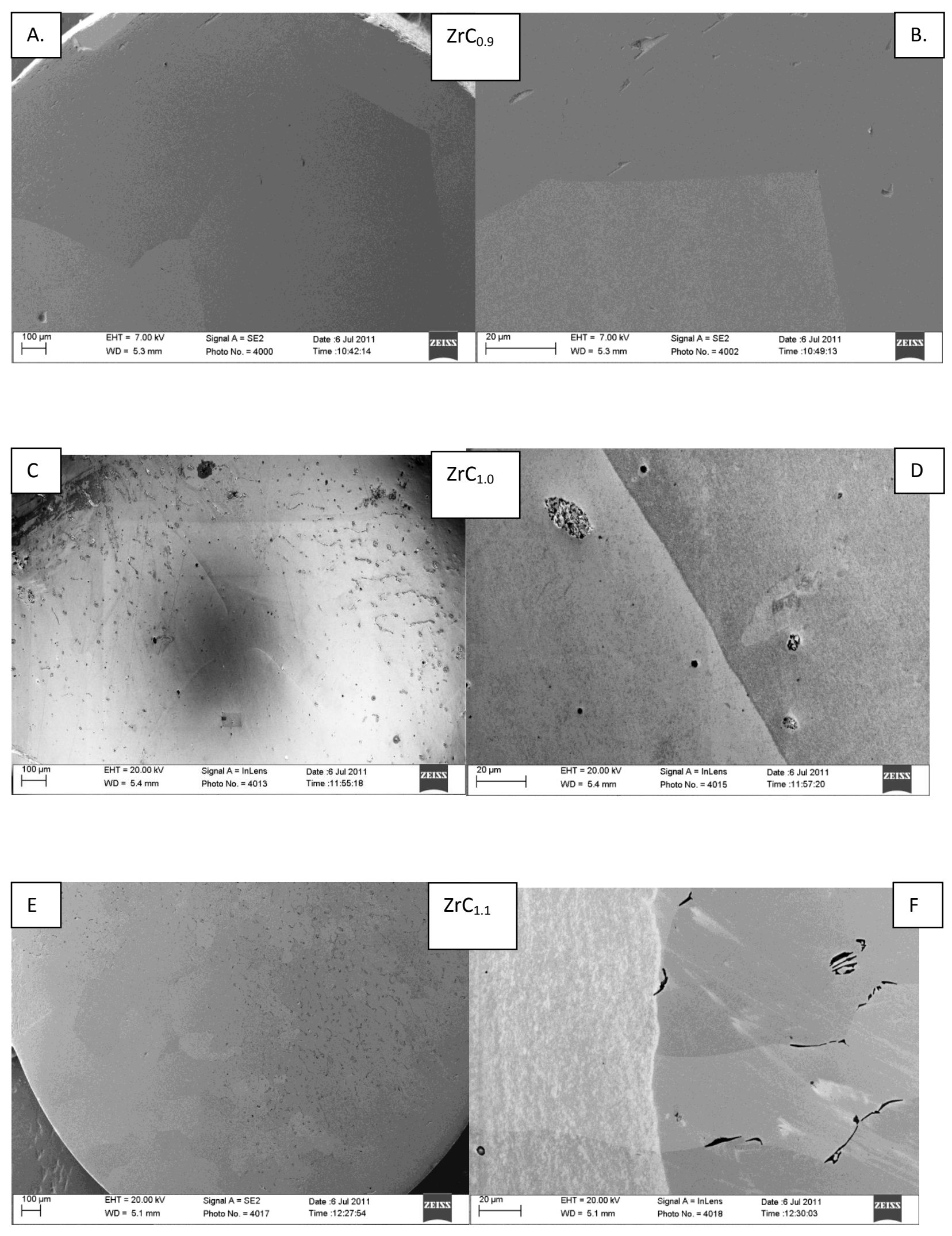


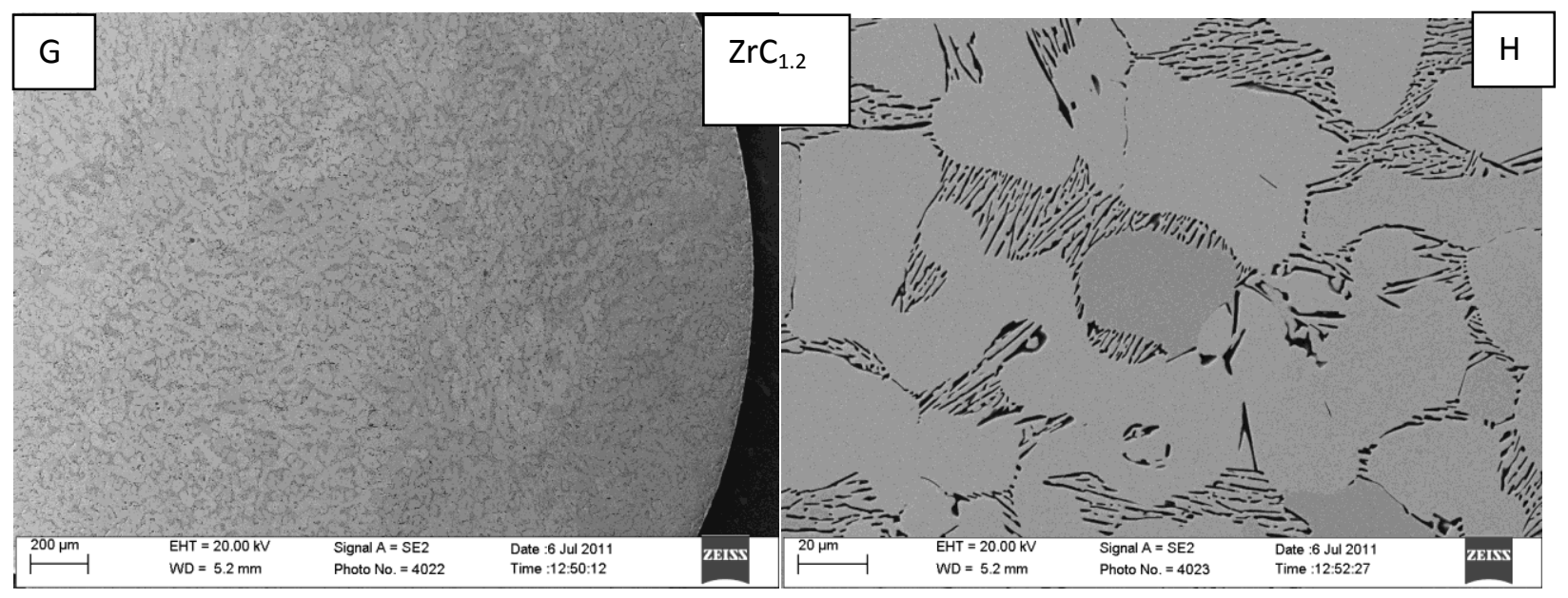

Figure 5. SEM of as-received zone refined $\mathrm{ZrC}_{\mathrm{x} .}(\mathrm{A}, \mathrm{C}, \mathrm{E}, \mathrm{G}$ are low-magnification; $B, D, F, H$ are relative high-magnification). 

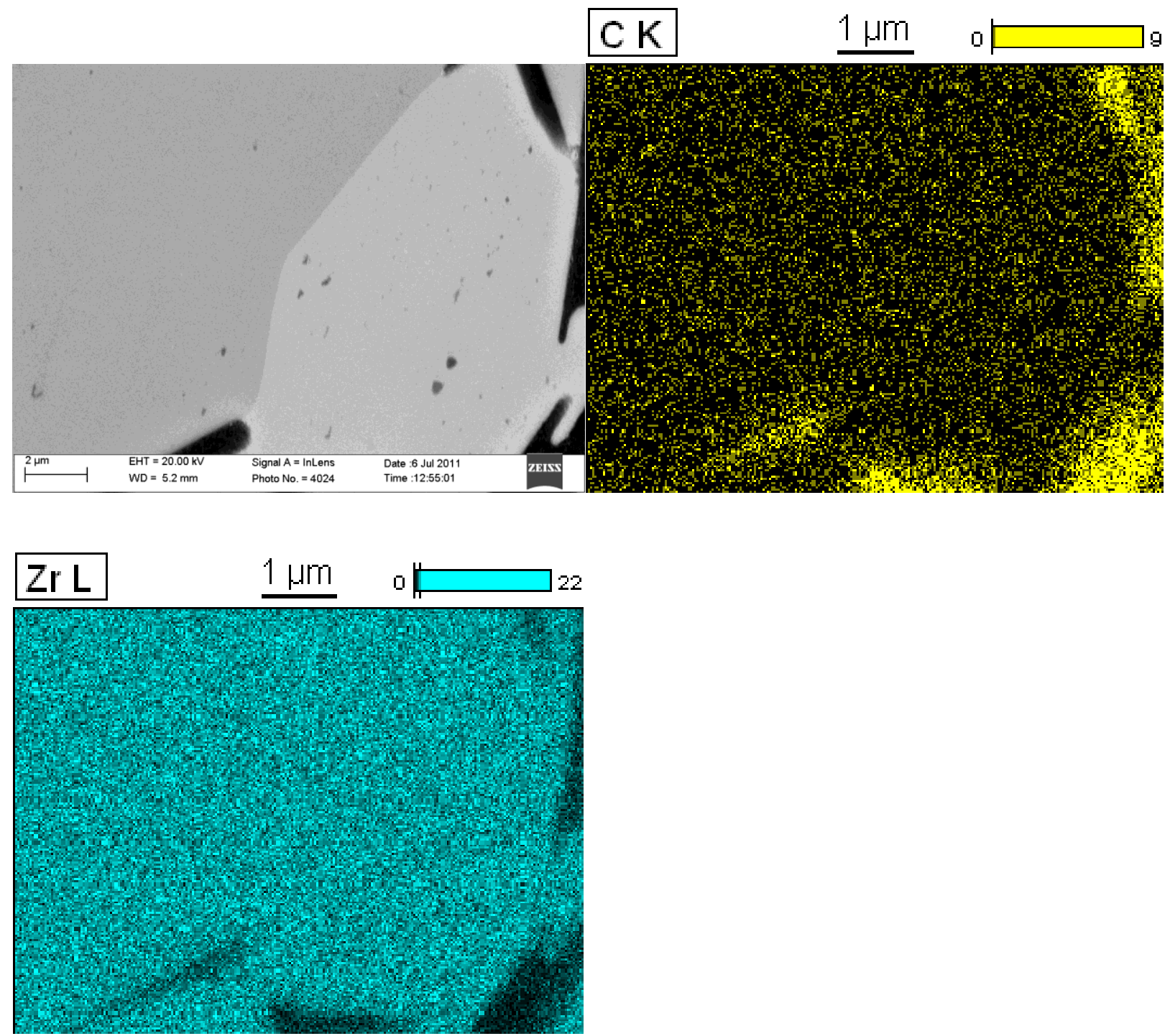

Figure 6. SEM-EDS elemental maps for $\mathrm{ZrC}_{1.2}$ which highlight the presence of pockets of excess graphite. 


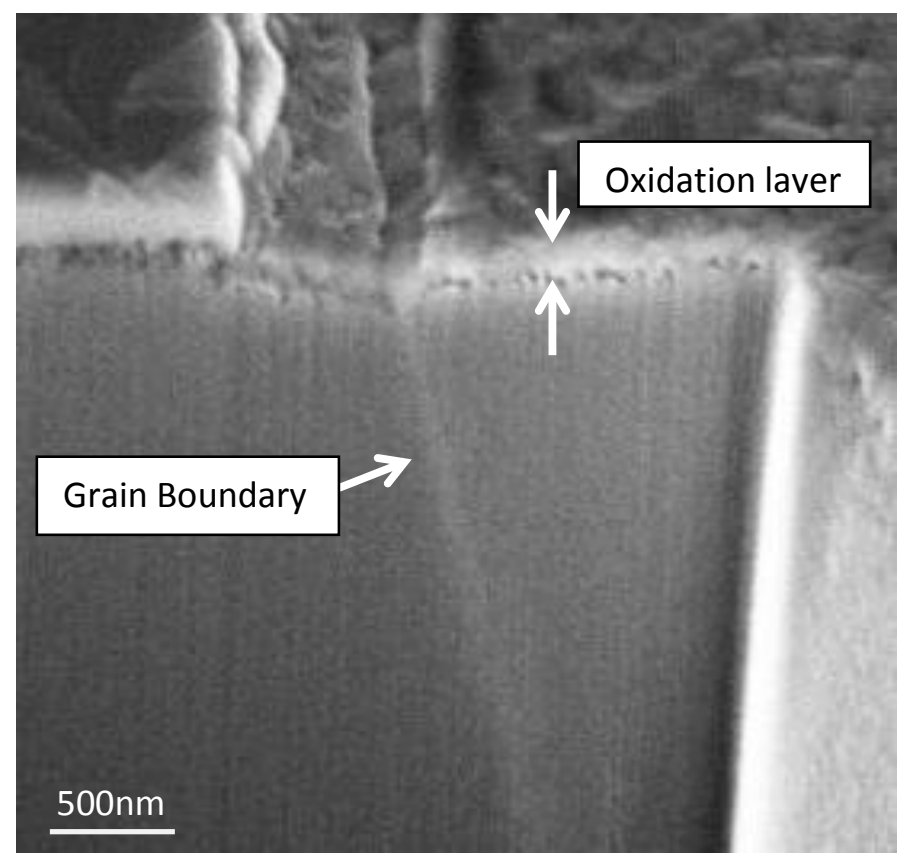

Figure 7. A cross-section SEM image for $\mathrm{ZrC}_{1.0}$ with a dose $2 \mathrm{dpa}$ reveals a very thin oxide layer has formed on the surface of the sample. 

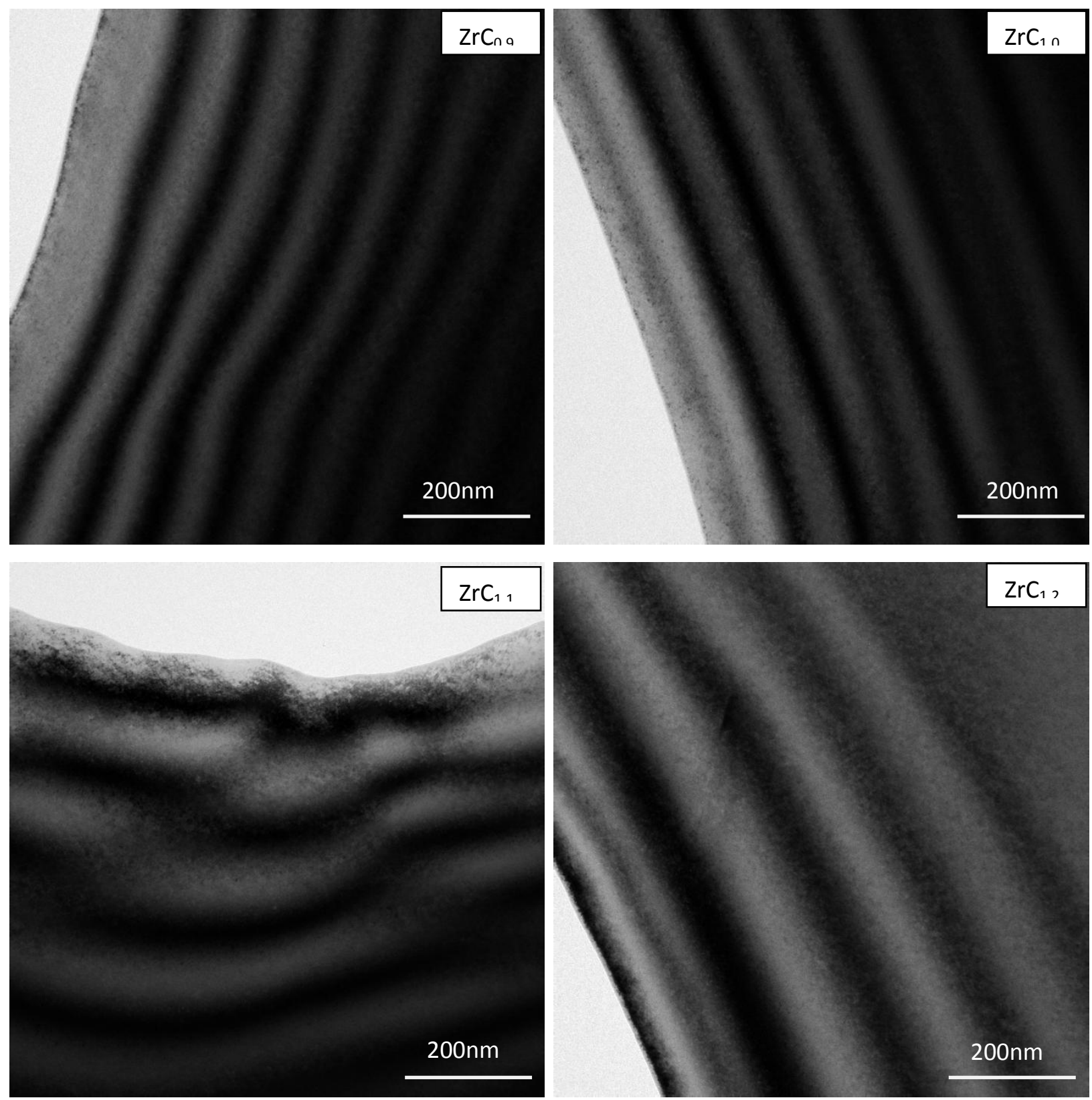

Figure 8. Bright Field (BF) images of un-irradiated $\mathrm{ZrC}_{\mathrm{x}}$. 

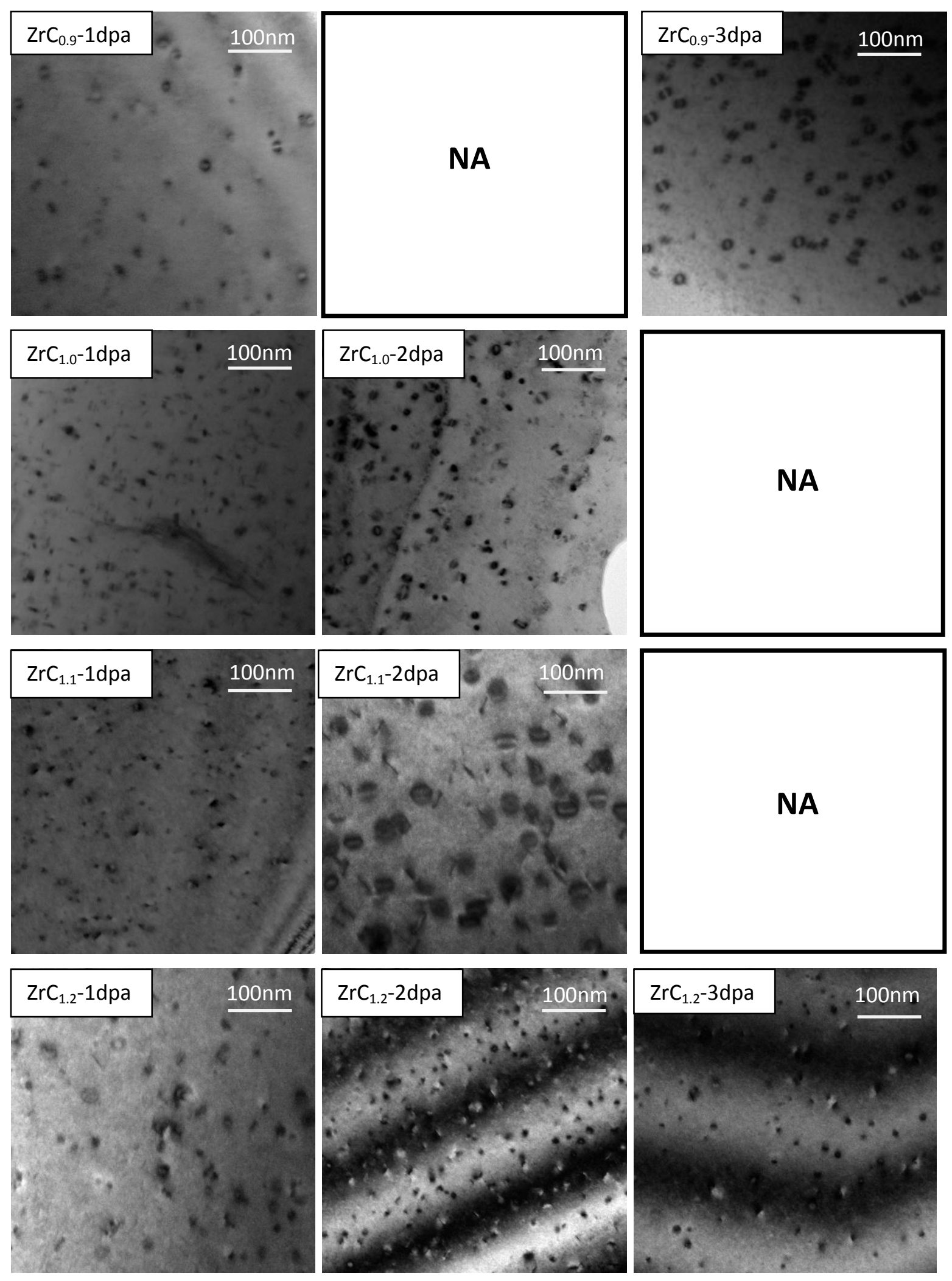

Figure 9. Bright Field (BF) images of $\mathrm{ZrC}_{\mathrm{x}}$ irradiated to $3 \mathrm{dpa}$ at $800^{\circ} \mathrm{C}$. 

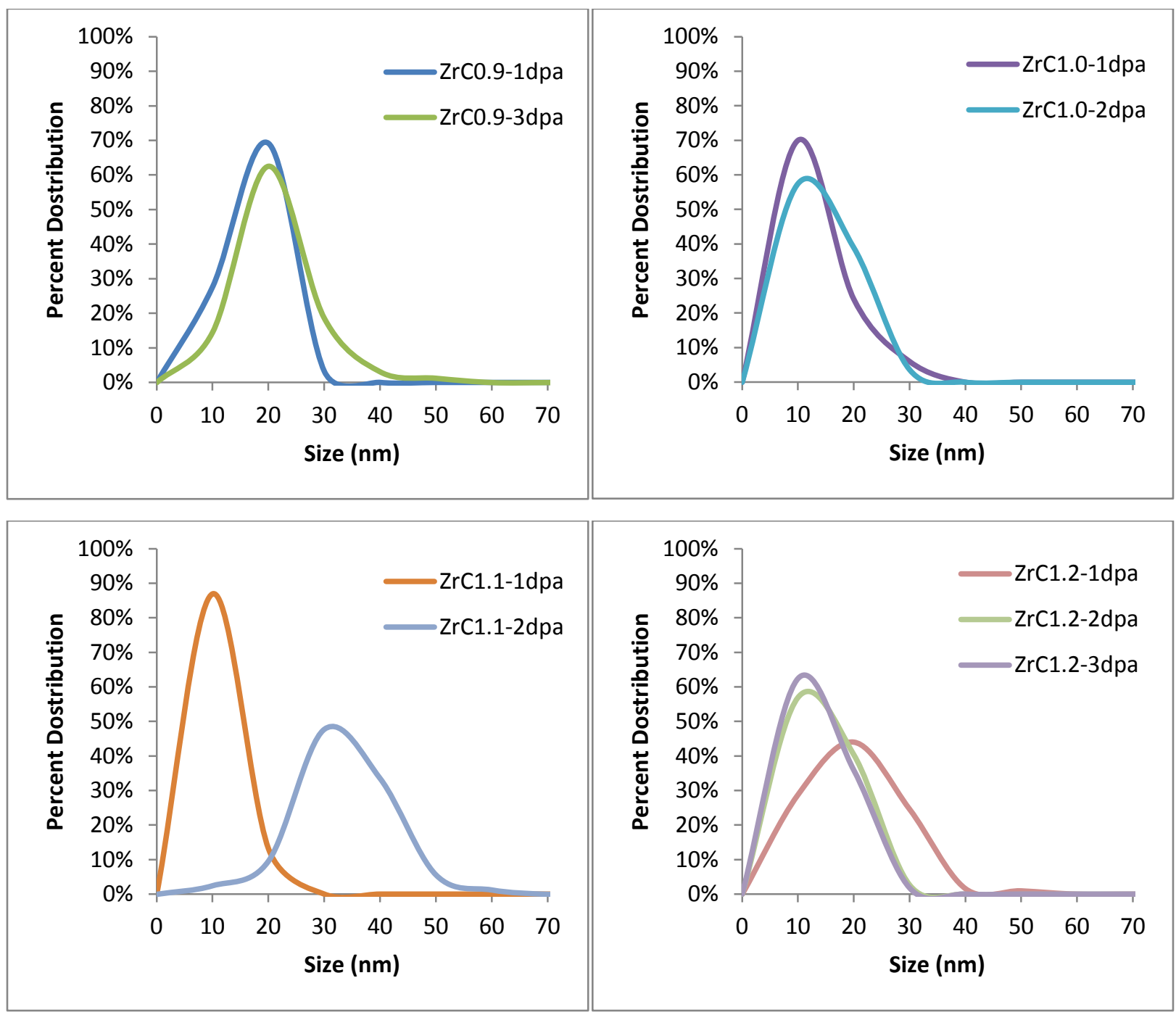

Figure 10. Dislocation loop size distributions in irradiated $\mathrm{ZrC}_{x}$. 


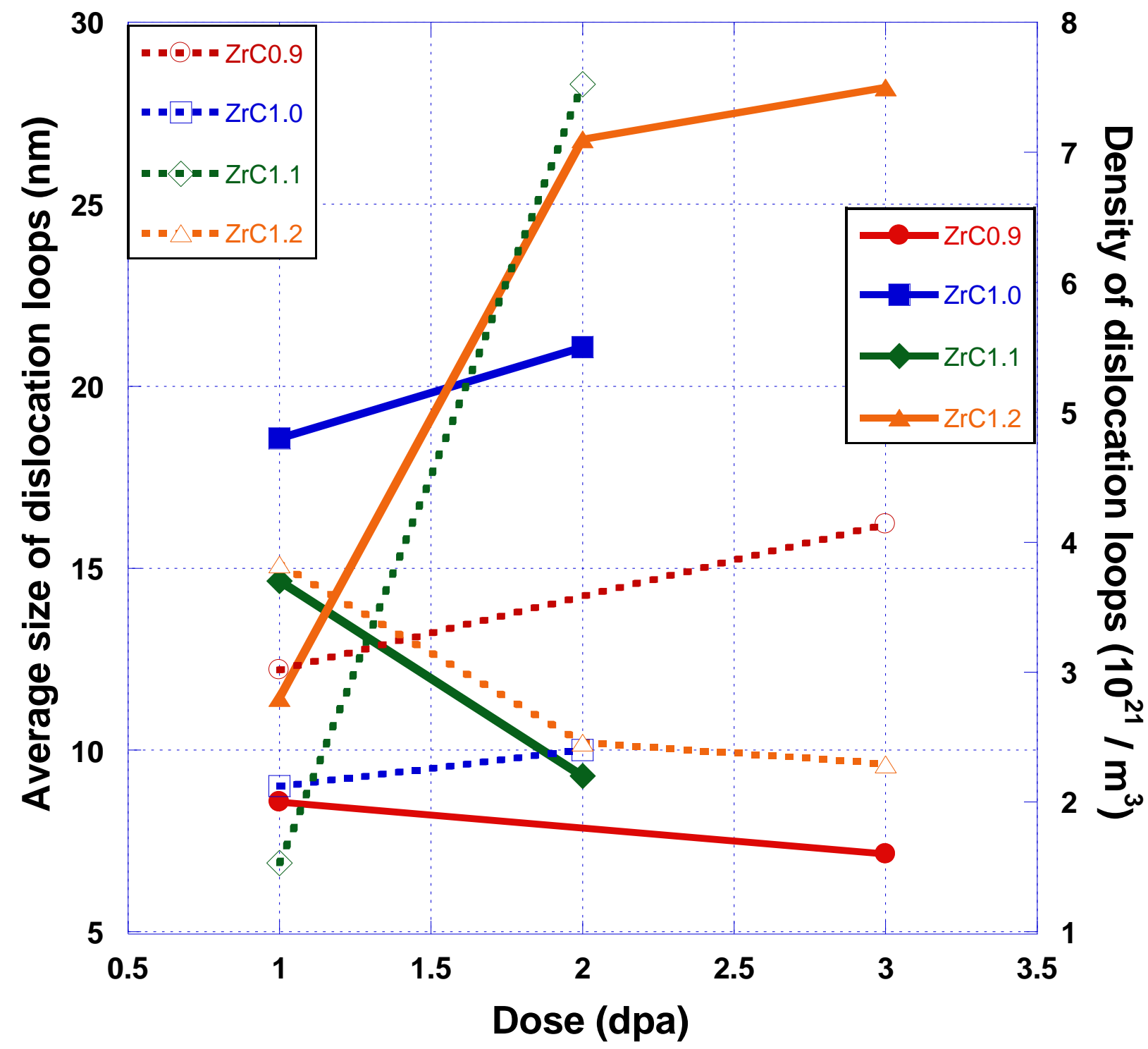

Figure 11. Average size of dislocation loops to stoichiometry and density of dislocation loops to stoichiometry in irradiated $\mathrm{ZrC}_{\mathrm{x}}$. 
Table 1. Numerical analysis of TEM data

\begin{tabular}{|l|c|c|c|}
\hline & Density $\left(10^{21} / \mathrm{m}^{3}\right)$ & Average loops size $(\mathrm{nm})$ & STDEV of loops size $(\mathrm{nm})$ \\
\hline $\mathrm{ZrC}_{0.9}-1 \mathrm{dpa}$ & 4.1 & 12.2 & 3.5 \\
\hline $\mathrm{ZrC}_{0.9}$-3dpa & 3.2 & 16.2 & 6.9 \\
\hline $\mathrm{ZrC}_{1.0}-1 \mathrm{dpa}$ & 9.7 & 9.0 & 4.9 \\
\hline $\mathrm{ZrC}_{1.0}-2 \mathrm{dpa}$ & 6.6 & 10.0 & 4.2 \\
\hline $\mathrm{ZrC}_{1.1}-1 \mathrm{dpa}$ & 5.2 & 6.9 & 2.9 \\
\hline $\mathrm{ZrC}_{1.1}-2 \mathrm{dpa}$ & 4.7 & 28.3 & 8.3 \\
\hline $\mathrm{ZrC}_{1.2}-1 \mathrm{dpa}$ & 5.5 & 15.1 & 7.2 \\
\hline $\mathrm{ZrC}_{1.2}-2 \mathrm{dpa}$ & 7.1 & 10.2 & 4.1 \\
\hline $\mathrm{ZrC}_{1.2}-3 \mathrm{dpa}$ & 7.5 & 9.6 & 3.8 \\
\hline
\end{tabular}

